\title{
济南市城市绿地可达性分析
}

\author{
尹海伟1 孔繁花 ${ }^{2}$ \\ （1 南京大学城市与资源学系, 南京 210093）（2 日本广岛大学国际协力研究科, 日本广岛 739-8529）
}

\begin{abstract}
摘 要 以济南市 1989、1996 和 2004 年 SPOT 遥感卫星影像数据解译的城市绿地分类图、道路图和水系图为基础 数据资料, 在遥感 (RS) 和地理信息系统 (GIS) 技术支持下, 运用景观可达性的概念与原理, 采用费用加权距离方法, 对济南市整体绿地系统和公园与广场绿地可达性的时空动态变化及其原因进行了分析。研究结果表明: 1)济南市 城市绿地的可达性不断提高与改善;2)济南市城市绿地可达性的空间格局变化明显,但仍不均衡、不太合理;3)城 市绿地面积和斑块数量的不断增加、绿地分布格局的日益均衡和道路网的日殝完善是可达性不断提高的主要原 因;4)城市绿地可达性分析是衡量城市绿地服务功能社会公平性的有力手段, 充分体现城市建设 “以人为本”的理 念, 是目前生态城市评价指标体系的必要补充。因此, 城市绿地可达性分析结果可为合理调整与设计城市绿地系 统提供科学依据。
\end{abstract}

关键词 城市绿地 可达性 费用加权距离 济南市

\section{ACCESSIBILITY ANALYSIS OF URBAN GREEN SPACE IN JINAN}

\author{
YIN Hai-Wei ${ }^{1}$ and KONG Fan-Hua ${ }^{2}$ \\ (1 Department of Urban and Resources Sciences, Nanjing University, Nanjing 210093, China) \\ (2 Graduate School for International Development and Cooperation, Hiroshima University, Higashi-hiroshima 739-8529, Japan)
}

\begin{abstract}
Urban green space is viewed as the last remnant of the nature in urban areas, and usually performs important ecological and socio-economic functions. In addition to protecting biodiversity, absorbing pollutants, and mitigating urban heat island, green spaces also can provide many social benefits such as amenity-recreation venues. Urban green spaces can usually play an important integrative social role if adequately designed and enhance urban livability from a social development perspective. There has been a surge in the concept of "ecocity", "garden city" and "sustainable city", and urban green spaces have become an important indicator of a city's character. Concomitantly, a series of evaluation systems were applied. However, most of these indictor systems lacked any social indicators about societal equity of urban green space. In this research, a quantitative method based on landscape accessibility of green space was put forward to improve the indictor systems.

Jinan was chosen as our case study. The basic landscape data were obtained from SPOT satellite images in the years of 1989, 1996 and 2004, and an urban green space map, a road network map and a watershed map were produced using remote sensing (RS) and geographic information system (GIS). Based on the concept and principle of landscape accessibility, a cost weighted distance analysis (in "Spatial Analyst" module of ARCMAP) was conducted to analyze the accessibility of urban green spaces, public parks and plaza-green space. Finally, the influencing factors for the spatio-temporal change of accessibility were explained in detail.

The results showed: 1) The methods used in this research were able to evaluate the distribution pattern and rationality of urban green space. 2) A comparison of urban green space accessibility across the three years indicated a significant overall increase. 3) The spatial pattern of accessibility also changed but still had high degrees of un-equilibrium and un-rationalization. 4) The main reasons for improved accessibility were increased urban green space area and patch numbers, a more balanced distribution pattern, and the gradually perfected road network. 5) Accessibility was an important indicator to weight the social equity of urban green space, which is an indicator of the satisfaction to all inhabitants. Accessibility is a necessary supplement to the indictor system presently used to evaluate eco-city. Recommendations for urban green space planning were put forth for government officials and planners to help optimize urban green space patterns in Jinan.
\end{abstract}

Key words Urban green space, Accessibility, Cost weighted distance, Jinan 
随着社会经济的发展, 人们越来越关注生活质 量, 而作为城市中唯一接近于自然生态系统的城市 绿地是反映一个城市生活质量的重要指标, 对保障 城市生态环境可持续发展和维护居民身心健康有着 至关重要的作用, 有些学者将城市绿地的这种作用 称为“自然的服务”( Nature” s service), 归入 “生态系 统的服务功能”( Daily，1997)。目前, 国内“生态城 市”、“园林城市”、“山水城市”等活动高潮迭起, 但评 价的指标体系却很不完善, 只重视绿地的面积和比 例指标, 缺乏绿地服务功能的公平性评价 (黄肇义和 杨东援，2001; 宋永昌等，1999; 张丽平和申玉铭， 2003), 而城市绿地的可达性 (Accessibility) 是体现绿 地资源享用的公平性和社会平等性的一个重要指 标, 也是生态城市所要实现的环境改善、经济发展、 社会平等 3 大目标之一, 弥补了目前生态城市评价 指标之不足 (Dominsk, 1992; Roseland, 1997; 黄辞海 和白光润, 2003; 程世丹, 2004)。

某一景观的可达性是指从空间中任意一点到该 景观的相对难易程度, 反映了景观对某种水平运动 的景观阻力 (Forman \& Godron, 1986; Knaapen et al., 1992; Forman, 1995; Yu, 1996, 俞孔坚等, 1999)。 许多学者采用可穿越性 (Boone \& Hunter，1996) 与隔 离程度 (Simberloff \& Wilson, 1969) 来表述, 但更为普 适性的概念是费用距离（Cost distance）（ESRI, 1991)。目前, “生态优先”、“以人为本”的城市规划 新理念已深入人心, 使城市绿地可达性分析开始受 到重视 (黄光宇和陈勇, 1997), 但景观可达性概念 和费用加权距离方法 (Cost weighted distance modeling) 主要用于评价城市服务设施(道路、图书馆、学 校及商业网点等)分布的合理性与公平性, 用于评价 城市绿地服务功能的公平性的例子不多 ( ESRI,

1991; Javier \& Gabriel, 1999; Harini et al., 2003)。 俞孔坚等(1999)曾采用此方法研究了中山市城市绿 地的可达性，但假设研究区内全部采用步行模式。 本文借助于 RS 和 GIS 技术, 设定步行 (在无城市干 道区域)和车行(在城市干道区域)两种移动模式, 采 用费用加权距离方法对济南市城市绿地可达性动态 变化及其原因进行了分析。

\section{1 研究区域}

济南市位于 $36^{\circ} 32^{\prime} \sim 36^{\circ} 51^{\prime} \mathrm{N}, 116^{\circ} 49^{\prime} \sim 117^{\circ} 14^{\prime}$
$\mathrm{E}$, 南依泰山山脉、北枕黄河; 属典型的温带半湿润 大陆性季风气候, 四季分明, 年平均气温 $14{ }^{\circ} \mathrm{C}$, 年平 均降雨量 $650 \sim 700 \mathrm{~mm}$; 南部泰山山脉属石灰岩且 岩层向北倾斜, 北部地层为火成岩, 因此从泰山岩层 南来的地下水在北部受到阻挡而形成许多泉水, 济 南由此而以“泉城”著称; 自然植被以针阔混交林和 常绿针叶林为主, 优势树种为法桐 (Platanus orientalis)、国槐 (Sophora japonica)、毛白杨 (Populus tomentosa) 和侧柏 ( Platycladus orientalis) 及一些草灌群 落1)。本文以济南市二环路以内区域为研究区, 总 面积为 $149.2 \mathrm{~km}^{2}$, 该区域为济南市的核心, 是城市 居民的主要分布区, 也是历届城市总体规划的核心 范围。

\section{2 研究方法}

\section{1 基础数据}

本研究所使用的主要数据有: 1) 1989 年 SPOT 图像(分辨率 $10 \mathrm{~m}$, 单波段), 1989 年 TM 图像(分辨 率 $30 \mathrm{~m}, 7$ 波段), 1996 年 SPOT 图像(分辨率 $10 \mathrm{~m}$, 单波段和分辨率 $20 \mathrm{~m}, 4$ 波段), 2004 年 SPOT 图像 (分辨率 $10 \mathrm{~m}, 4$ 波段); 2) 2000 年绘制的地形图 (1:10 000);3)济南市规划局和济南市统计局提供 的城市规划及统计数据。

\section{2 分析过程与方法}

本文所需数据的获取、处理与城市绿地可达性 分析过程如图 1 所示。

首先, 基于 ERDAS 软件平台对 1989、1996 和 2004 年的遥感影像进行校正及融合并创建墨卡托 投影坐标系统 (Universal transverse mercator projection, $\mathrm{UTM}$ ); 其次, 在 ARC/INFO 软件平台的 ARCMAP 中, 参考地形图和野外调查资料, 采用目视判读解译方 法获得济南市城市绿地空间分布图, 根据研究绿地 社会服务功能公平性的需要, 同时参考国家的划分 标准, 本文仅选取服务功能较好且向市民开放的公 园绿地、广场绿地、风景林、河流水域绿地 4 类作为 研究对象 (表 1, 图 2)。

然后, 采用费用距离方法, 使用 ARCMAP 中的 Spatial Analyst 模块的 Distance/Cost Weighted 工具进 行城市绿地可达性分析。相对时间成本值 (Time cost weighted value)采用城市居民通过空间某一像元 $(5 \mathrm{~m} \times 5 \mathrm{~m})$ 的相对难易程度来衡量, 本文采用的时 


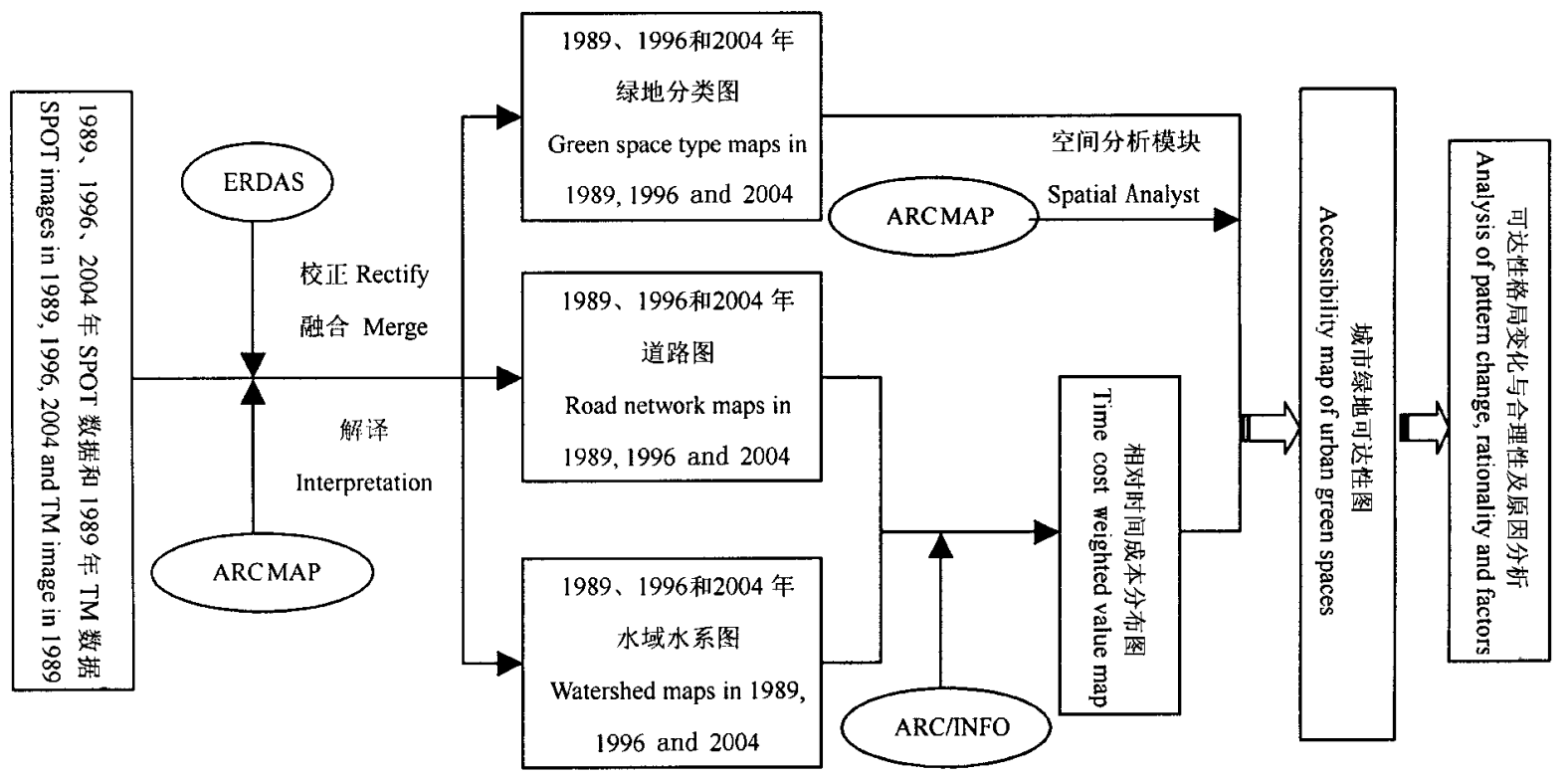

图 1 研究区城市绿地可达性数据处理与分析流程图

Fig. 1 Flow chart of the analysis processing of urban green space accessibility

表 1 济南市 4 类城市绿地主要特征

Table 1 Description of four urban green spaces in Jinan City

绿地分类 Green space types

公园绿地 Public park

广场绿地 Plaza-green space

河流水域绿地 Riparian green space

风景林 Scenery forest
特征 Description

生物多样性较高, 向公众开放; 以生态、娱乐、休㮩和社会文化功能为主

Open to the public and high diversity; provides ecology, recreation and social culture

生物多样性较低, 向公众开放; 以娱乐、休悡、商业和社会文化功能为主

Open to the public and low diversity; provides recreation, business and social culture

河流和水域旁的线形生态廊道, 向公众开放; 以娱乐、休唕功能为主

Open to the public and linear corridors along watersheds; provides recreation

生物多样性较高, 向公众开放; 以生态、娱乐和休喤功能为主

Open to the public and high diversity; provides ecology and recreation

表 2 不同土地利用类型相对时间成本值

Table 2 Time cost weighted value of different land use types

\begin{tabular}{cccc}
\hline 土地利用类型 Land use type & 干道 Road network & 无道路地区 No road area & 水域 Watershed \\
\hline 相对时间成本值 Time cost weighted value & 30 & 120 & 1000 \\
\hline
\end{tabular}

间成本值为移动 $10 \mathrm{~km}$ 所需要的分钟数, 并设定步 行时速平均为 $5 \mathrm{~km} \cdot \mathrm{h}^{-1}$, 车行时速平均为 $20 \mathrm{~km} \cdot$ $\mathrm{h}^{-1}$, 因而交通干道和无干道区域的相对时间成本值 分别为 30 和 120 , 而河流水域由于其对城市斑块的 分割性,一般要绕行一定距离才能到达对岸, 鉴于 此,本文将其相对时间成本值设定为 1000 (表 2)。 公园和广场绿地最具生态、游憩与社会文化功能, 因 而对市民的可达性意义也最为重要, 本文对其可达
性进行了单独分析, 因此可达性分析将分别以整体 绿地系统和公园与广场绿地斑块作为 “源” (Source) 来进行计算, 计算结果与绘制的可达性分布图 $(5 \mathrm{~m}$ $\times 5 \mathrm{~m}$ 的栅格图) 见表 3、4, 图 3、4。为了定量分析可 达性的空间格局及其变化, 本文以经三路纬一路交 叉口为中心将研究区平分为 8 个象限 (图 1), 按象 限统计 5 min 可达区和 15 min 可达区面积, 并进行 了相关分析(图 5.6)。 
表 3 整体绿地系统可达性变化

Table 3 Accessibility changes of urban green space system

\begin{tabular}{cccc}
\hline 年份 Year & 1989 & 1996 & 2004 \\
\hline$<5$ 分钟 < $5 \mathrm{~min}$ & $4392 \mathrm{hm}^{2}, 35.47 \%$ & $5315 \mathrm{hm}^{2}, 42.25 \%$ & $6053 \mathrm{hm}^{2}, 49.19 \%$ \\
$5 \sim 15$ 分钟 5-15 min & $6167 \mathrm{hm}^{2}, 49.80 \%$ & $6281 \mathrm{hm}^{2}, 49.92 \%$ & $5726 \mathrm{hm}^{2}, 46.53 \%$ \\
$15 \sim 30$ 分钟 $15-30 \mathrm{~min}$ & $1657 \mathrm{hm}^{2}, 13.38 \%$ & $980 \mathrm{hm}^{2}, 7.79 \%$ & $523 \mathrm{hm}^{2}, 4.25 \%$ \\
$>30$ 分钟 > 30 min & $167 \mathrm{hm}^{2}, 1.35 \%$ & $6 \mathrm{hm}^{2}, 0.05 \%$ & $3 \mathrm{hm}^{2}, 0.02 \%$ \\
\hline 面积为不同时间内可达区域的面积, 百分比为同一年份不同可达区域面积占可达性总面积的比例 Area represents the area of accessible region
\end{tabular}
in 1989, 1996 and 2004, respectively. Percentage equals the area of accessible region divided by the total accessible area

表 4 公园与广场绿地可达性变化

Table 4 Accessibility changes of public park and plaza-green space

\begin{tabular}{cccc}
\hline 年份 Year & 1989 & 1996 & 2004 \\
\hline$<5$ 分钟 < 5 min & $1279 \mathrm{hm}^{2}, 8.86 \%$ & $1517 \mathrm{hm}^{2}, 10.46 \%$ & $2151 \mathrm{hm}^{2}, 14.94 \%$ \\
$5-15$ 分钟 5-15 min & $3769 \mathrm{hm}^{2}, 26.10 \%$ & $3908 \mathrm{hm}^{2}, 26.96 \%$ & $5894 \mathrm{hm}^{2}, 40.94 \%$ \\
$15-30$ 分钟 $15-30 \mathrm{~min}$ & $4404 \mathrm{hm}^{2}, 30.50 \%$ & $4761 \mathrm{hm}^{2}, 32.84 \%$ & $4903 \mathrm{hm}^{2}, 34.05 \%$ \\
$30-60$ 分钟 $30-60 \mathrm{~min}$ & $3585 \mathrm{hm}^{2}, 24.83 \%$ & $3960 \mathrm{hm}^{2}, 27.32 \%$ & $1424 \mathrm{hm}^{2}, 9.89 \%$ \\
$>60$ 分钟 $>60 \mathrm{~min}$ & $1404 \mathrm{hm}^{2}, 9.72 \%$ & $350 \mathrm{hm}^{2}, 2.41 \%$ & $26 \mathrm{hm}^{2}, 0.18 \%$ \\
\hline
\end{tabular}

下注同表 3 Notes are the same as Table 3

\section{3 结果分析}

\section{1 济南城市绿地可达性明显改善}

由表 3、4 可见, 整体绿地系统和公园与广场绿 地的可达性均有较大提高。5 min 可达区面积分别 由 1989 年的 4392 和 $1279 \mathrm{hm}^{2}$ 增为 1996 年的 5315 和 $1517 \mathrm{hm}^{2}, 2004$ 年的 6053 和 $2151 \mathrm{hm}^{2}$, 所占可达 性总面积 (即研究区面积减去源的面积)的比例分别 由 1989 年的 $35.47 \%$ 和 $8.86 \%$ 增为 1996 年的 $42.25 \%$ 和 $10.46 \%$ 及 2004 年的 $49.19 \%$ 和 $14.94 \%$; 15 min 可达区面积所占可达性总面积的比例分别由 1989 年的 $85.27 \%$ 和 $34.96 \%$ 增为 1996 年的 $92.17 \%$ 和 $37.42 \%$ 和 2004 年的 $95.72 \%$ 和 $55.88 \%$ 。

由图 3 可见,整体绿地系统可达性的明显改善 主要位于济南市北部( 小清河以北地区)、中部偏西 地区 (即兴济河以东、经十路与经一路以北、济泺路 以西、无影山中路以南的区域)和东部(即历山路以 东、经十路以北、二环东路以西、山大南路以南的区 域)。

由图 4 可见, 公园与广场绿地可达性的明显改 善主要位于济南市的北部( 小清河以北地区)、西部 (即二环西路以东、经十路与经一路以北、济泺路以 西、小清河北路以南的区域)和西南部(即白马山与 济南南站的周边区域)。

3.2 济南城市绿地可达性空间格局仍不均衡、不太 合理

由图 5.6 可见, 整体绿地系统和公园与广场绿
地的 5、15 min 可达区面积在 8 个象限内分布变化均 十分明显, 说明济南城市绿地的可达性格局变化明 显, 且呈现“点源扩散”的变化模式(图 3、4); 济南城 市绿地的空间分布格局一直很不均衡, 且公园与广 场绿地可达性不均衡程度要明显高于整体绿地系 统。

由图 5 可见,整体绿地系统的 5 min 可达区面积 分布 1989 年在第 4 象限为峰值, 1996 年在第 $1 、 4$ 象 限为峰值, 2004 年在第 8 象限为峰值, 这说明 1989 ～ 1996 年济南城市绿地可达性在第 1 象限改善最 为明显, $1996 \sim 2004$ 年在第 8 象限可达性变化最明 显; 公园与广场绿地的可达区面积分布 1989 2004 年均在第 2 象限为峰值, 但 1996 年在第 6 象限变化 最大, 2004 年在第 8 象限变化最大, 这说明 1989 2004 年济南公园与广场绿地的可达性在第 2 象限 一直保持最高, 1989 1996 年在第 6 象限可达性改 善最为明显, $1996 \sim 2004$ 年在第 8 象限可达性变化 最明显。

由图 6 可见,整体绿地系统的 $15 \mathrm{~min}$ 可达区面 积分布 1989 年在第 3.5 象限出现较为明显的谷值, 1996 年在第 $1 、 8$ 象限变化最明显, 2004 年在第 7 象 限有较大变化, 这说明 1989 年济南城市绿地可达性 在第 3、5 象限最差, 1989 1996 年在第 $1 、 8$ 象限可 达性改善最为明显, $1996 \sim 2004$ 年在第 7 象限可达 性变化较大; 公园与广场绿地的可达区面积分布 1989 年在第 2 象限为峰值, 而在第 1、5 7 象限为低 值区, 1996年在第6、7象限变化最大, 2004年在第 


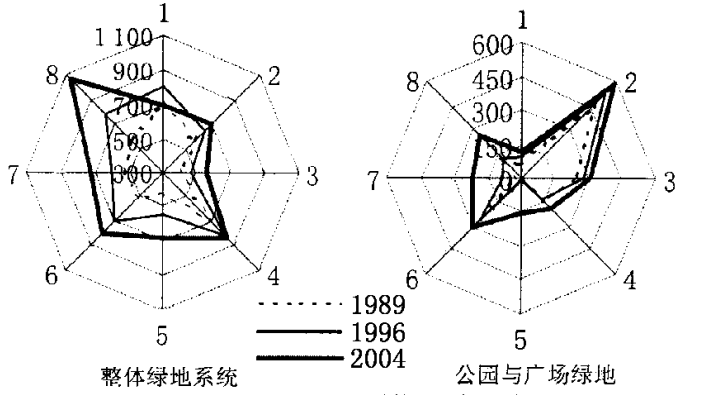

urban green space system

Public park and plaza-green space

图 5 不同时期 $5 \mathrm{~min}$ 可达区面积 $\left(\mathrm{hm}^{2}\right)$

Fig.5 Accessibility area in 5 minutes in different periods $\left(\mathrm{hm}^{2}\right)$

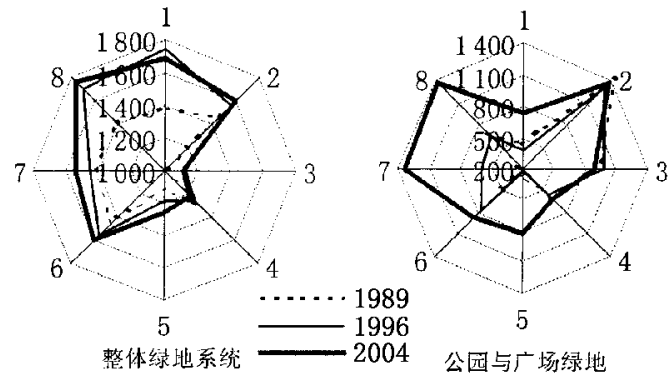

Urban green space system Public park and plaza-green space

图 6 不同时期 $15 \mathrm{~min}$ 可达区面积 $\left(\mathrm{hm}^{2}\right)$

Fig.6 Accessibility area in 15 minutes in different period $\left(\mathrm{hm}^{2}\right)$

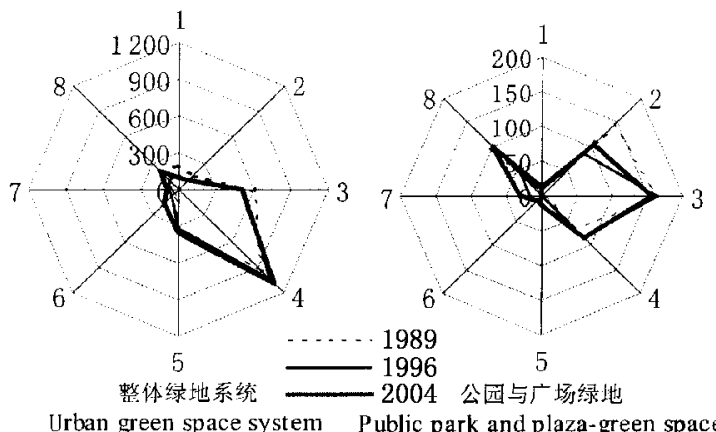

图 7 绿地面积分布 $\left(\mathrm{hm}^{2}\right)$

Fig.7 Area distribution of urban green space $\left(\mathrm{hm}^{2}\right)$

1、5、7、8 象限变化较大, 这说明 1989 年济南公园与 广场绿地的可达性在第 2 象限最高, 而在第 $1 、 5 \sim 7$ 象限可达性较低, 1989 1996 年在第6.7 象限可达 性改善最为明显, 1996 2004 年在第 1 、5、7、8 象限 可达性变化较大。

可达性越均衡说明各象限内的市民享受绿地服 务功能的机会越公平。通过以上分析发现, 济南城
市绿地的可达性分布格局虽有很大改善仍很不均 衡, 因此, 目前可达性空间分布格局未能使人们公平 享用绿地的服务功能, 说明其仍不太合理。

\section{3 济南城市绿地可达性提高的主要原因分析}

城市绿地可达性的提高主要与绿地面积和斑块 数量不断增加、绿地空间分布格局日趋均衡和道路 网的日殝完善有关。3 个因素共同作用,但在不同 时期不同地区(象限), 其作用大小有别。

济南市整体绿地系统可达性改善主要与绿地斑 块数量增加和道路网络不断完善有关, 与绿地面积 相关性不大 (图 2、7); 1989 1996 年在第 1、8 象限即 济南市北部可达性明显改善主要是受道路网密度明 显增加的影响, 另外也与河流水域绿地 (如小清河两 侧的绿地)不断被蚕食和分割有关，而 1996 2004 年在第 $7 、 8$ 象限即济南市西北部可达性明显改善主 要是受绿地斑块数量增加的影响, 新增的绿地斑块 主要有药山公园、绿苑广场等(图 2)。

济南市公园与广场绿地可达性改善主要与绿地 面积斑块数量增加、绿地空间分布格局日趋均衡和 道路网络不断完善有关 (图 2、4、7); 1989 1996 年 在第 6.7 象限即济南市西部可达性明显改善主要是 由绿地面积和斑块数量增加引起的, 新增的绿地斑 块主要有森林公园、段店公园、匡山公园等,而 1996 ～ 2004 年在第 1 、7、8 象限即济南市西北部可达性明 显改善主要是由道路网络不断完善和绿地斑块数量 增加共同引起的, 新增的绿地斑块主要有黄台公园、 药山公园、黄冈公园等(图 2、4); 总体上可达性的格 局有了很大的改善, 改变了原来中东部可达性高周 围低的格局, 西部、北部可达性都有了明显改善, 这 主要是绿地分布格局日益均衡的结果(图 4)。

济南市绿地面积和斑块数量不断增加、绿地空 间分布格局日趋均衡和道路网的日臻完善均受到济 南市政府政策的显著影响。济南市城市总体规划 （1996～2010)、“济南五年大变样”方案(1997 年)和 “争创国家园林城市”行动纲要以及“退二进三”城市 空间结构调整战略等制定并实施以来, 济南市共进 行了五个阶段的绿化工作, 并提出了“一环三带九 楔”的城市绿化空间布局结构和“楔形插入、点式分 布、网状连接、垂直绿化”的绿化方针, 使济南市城市 绿地面积不断增加 (绿地总面积由 1989 年的 2532 $\mathrm{hm}^{2}$ 增为 2004 年的 $2602 \mathrm{hm}^{2}$, 其中公园与广场绿地 面积由 1989 年的 $476 \mathrm{hm}^{2}$ 增为 2004 年的 $511 \mathrm{hm}^{2}$ ), 绿地空间格局趋于合理(西部和北部绿地面积和斑 块数量逐渐增加), 城市空间布局不断调整, 城市东 
进西扩, 道路网络也日㮹完善( 济南市规划局, $2003)^{1)}$ 。

\section{4 结论与讨论}

城市绿地是指城市中具有一定量的植被覆盖, 且植被主要以自然或半自然形态存在的区域 ( Jim \& Chen, 2003)。根据中国城市绿地划分标准 (CJJ/ T85-2002) 可将其划分为公园绿地、生产绿地、防护 绿地、附属绿地和其它绿地 5 大类、 13 中类、 11 小 类, 但社会文化服务功能较强且对城市居民影响较 大的绿地类型主要为公园绿地、广场绿地、河流水域 绿地和风景林, 因而本文选取此 4 类绿地进行可达 性的分析。

济南市城市绿地可达性格局变化分析结果表 明: 1) 1989 2004 年济南市城市绿地的可达性不断 提高与改善, 这说明近年来济南市政府采取的一系 列绿化措施收效较为显著; 2) 济南市城市绿地可达 性的空间格局仍不均衡、不太合理, 这主要与济南市 绿地分布格局、绿地面积和斑块数量和道路网络的 完善程度有关。因此, 今后济南市政府应着力解决 好新增城市绿地特别是公园与广场绿地的空间布局 问题; 通过土地置换和征购等多种途径增加中心城 区的绿地面积和斑块数量, 以解决中心城区大型公 共绿地不足的问题; 大力发展城市高速交通网络, 加 快城市高架路和轻轨的可行性设计及建设, 提高中 心城区的道路通过能力和平均行进速度。

城市绿地是城市中唯一残存的自然景观, 通常 具有重要的生态功能, 如保护生物多样性、防治水土 流失、减轻城市热岛效应等, 另外还具有重要的社会 文化功能, 如提供休息娱乐场所、提供大型公共活动 空间、减轻城市人的工作压力等。通过设定相对时 间成本值, 在 ARC/INFO 软件平台的支持下, 使用 ARCMAP 中的 Spatial Analyst 模块, 采用费用加权距 离方法对不同时期城市绿地的可达性进行评价, 是 衡量城市绿地所提供的生态及社会服务功能公平性 的有力手段, 是目前生态城市评价指标体系的必要 补充。可达性指标强调城市绿地空间分布格局和城 市绿地服务功能的社会公平性, 充分体现城市建设 “以人为本”的理念。因此, 可为合理调整与设计城 市绿地系统提供科学依据。

本文济南市城市绿地可达性的计算还存在一些
问题: 不同土地利用类型上的相对时间成本值设置 比较简单; 假设济南市城市人口分布是均匀的; 假设 人的运动速度是均匀的等。因此, 如何科学合理的 设定不同土地利用类型上的相对时间成本值并使其 具备在不同城市间进行横向比较的研究, 以及如何 将人口的空间分布与人运动时的疲劳程度等因素融 合到费用加权距离模型中进行更为准确的可达性分 析, 将是今后研究需要解决的关键问题。

\section{参 考 文 献}

Boone RB, Hunter MLJ (1996). Using diffusion models to simulate the effects of land use on grizzly bear dispersal in the Rochy Mountains. Landscape Ecology, 11, 51 - 64.

Cheng SD (程世丹) (2004). Concept and practice of ecological community. Engineering Journal of Wuhan University (武汉大 学学报 (工学版)), 37(3), 83-87. (in Chinese with English abstract)

Daily G (1997). Nature's Services: Society Dependence on Natural Ecosystems. Island Press, Washington, 25-34.

Dominsk T (1992). The three-stage evolution of eco-cities-reduce, reuse, recycle. In: Bob W, Lois A, Richard C eds. Sustainable Cities: Concepts and Strategies for Eco-City Development. Eco-home Media, 16 - 18.

ESRI (1991) . Cell-Based Modeling with GRID. Environmental Systems Research Institute, INC.

Forman RTT, Godron M (1986). Landscape Ecology. John Wiley \& Sons, New York, $74-87$.

Forman RTT (1995). Land Mosaics: the Ecology of Landscapes and Regions . Cambridge University Press, Cambridge, 32-41.

Harini N, Jane S, Catherine T (2003) . Accessibility as a determinant of landscape transformation in western Honduras: linking pattern and process. Landscape Ecology, 18, 141 - 158 .

Huang CH (黄辞海), Bai GR (白光润) (2003). On the connotation and indexes of residential eco-community. Human Geography (人文地理), 18 (1), 53-56. (in Chinese with English abstract)

Huang GY (黄光宇), Chen Y (陈勇) (1997). The conception of eco-city and study on urban planning and design method . City Planning Review (城市规划)，21 (6)，17-20. (in Chinese with English abstract)

Huang ZY (黄肇义), Yang DY (杨东援) (2001). The theoretical approach of the ecological city. City Planning Review (城市 规划), 25(1), 59-66. (in Chinese with English abstract)

Javier G, Gabriel G (1999). The important of orbital motorways on intrametropolitan accessibility: the case of Madrid's M-40. Journal of Transport Geography, 7, 1-15.

Jim CY, Chen SS (2003). Comprehensive green space planning

1）Jinan Urban Planning Bureau（济南市规划局)（1996）. Master Plan of Jinan City（1996-2010）(济南市城市总体规划（1996～2010）． Local Record Press, Jinan, $12-114$. (in Chinese) 
based on landscape ecology principles in compact Nanjing city, China. Landscape and Urban Planning, 65, 95 - 116.

Jinan Urban Planning Bureau (济南市规划局) (2003). Great Changes of Jinan City in Five Years (济南五年大变样). Jinan Press, Jinan, 4-24. (in Chinese)

Knaapen JP, Scheffer M, Harms B (1992) . Estimating habitat isolation in landscape planning. Landscape and Urban Planning, $23,1061-1073$.

Roseland M (1997). Dimension of the future: an eco-city overview. In: Roseland M ed. Eco-City Dimensions, Healthy Community Planet. New Society Publishers, Gabriola Island, BC, $1-13$.

Simberloff DS, Wilson EO (1969) . Experimental zoogeography of islands: the colonization of Empty Island. Ecology, 50, 278 286.

Song YC (宋永昌), Qi RH(戚仁海), You WH (由文辉), Wang
XR (王祥荣)，Zhu LB (祝龙彪) (1999). A study on indices system and assessment criterion of eco-city. Urban Environment \& Urban Ecology (城市环境与城市生态), 12(5), 16-19. (in Chinese with English abstract)

Yu KJ (1996). Security patterns and surface model in landscape planning. Landscape and Urban Planning, 36, 1 - 17 .

Yu KJ (俞孔坚), Duan TW (段铁武), Li DH (李迪华), Peng JF (彭晋福) (1999). Landscape accessibility as a measurement of urban green system. City Planning Review (城市规划), 23 (8), 8-11. (in Chinese with English abstract)

Zhang LP (张丽平), Shen YM (申玉铭) (2003). The study for Beijing eco-city synthetically evaluation. Journal of Capital Normal University (Natural Science Edition) (首都师范大学学报 (自然科学版) ), 24(3), 79-83. (in Chinese with English abstract) 